\title{
Innovation Policy Coherence for Sustainable Development
}

\author{
Vitaliy Omelyanenko ${ }^{1,2}$, Olha Prokopenko ${ }^{1}$, and Olena Omelyanenko ${ }^{2 *}$ \\ ${ }^{1}$ Teadmus OÜ, Estonia \\ ${ }^{2}$ Makarenko Sumy State Pedagogical University, Ukraine \\ ${ }^{3}$ Institute of Industrial Economics of NAS of Ukraine, Ukraine
}

\begin{abstract}
The research deals with the conceptual framework of innovation policy coherence for sustainable development. Authors prove that for the development of the national system, «sustainable development - security» should be considered innovation policy as a set of management tools for targeted implementation of innovations that will promote sustainable development. As a result of understanding the importance of SDGs, a scientific and practical approach to policy coherence for sustainable development (PCSD) is considered. Given the importance of innovation development and the national characteristics of the relationship between it and the SDGs, it is advisable to consider the methodology of coherence of innovation policy for sustainable development (innovation policy coherence for sustainable development, IPCSD). The context of innovation policy coherence for sustainable development based on ideas of theorists of economic science, innovation and strategic management is presented. It is proposed to implement the conceptual provisions of innovation policy coherence for sustainable development on the basis of adapted principles of sustainable development and principles of the relationship "sustainable development - security». Keywords: innovation policy, sustainable development, coherence, strategic management, security.
\end{abstract}

\section{Introduction}

The security problem is the main one on the list of priorities of the country's strategic development. It covers the complexity of transformation processes at the beginning of the XXI century and is a condition and goal of development policy, as it requires the concentration of all forces and resources on solving problems. Their diversion to neutralize threats complicates, and sometimes makes impossible, the successful implementation of development strategies. The existence of two primary and closely interrelated functions of the state - promoting socio-economic development and national security - raises the question of them in a closer union in a single functional system «development - security» in the transition to sustainable development as a basis for security.

To conceptualize the link between sustainable development and security, particularly

\footnotetext{
* Corresponding author: elnikkrasnaya@gmail.com
} 
within the sustainable development goals (SDGs), and to develop appropriate policies, it is necessary to find the most effective management tools, one of which, research has shown, is innovation policy.

Therefore, the purpose of this study is to determine the conceptual framework of innovation policy coherence for sustainable development.

\section{Innovation component of sustainable development}

The value of the innovation component is illustrated by the results of dispersion decomposition and identification of differences in how each SDG contributes to explaining the variance in the welfare of countries (Figure 1), according to which SDG 9 has the most considerable contribution (13\%) among other SDGs. The importance of SDG 9 can also be illustrated by the relationship between SDGs [1].

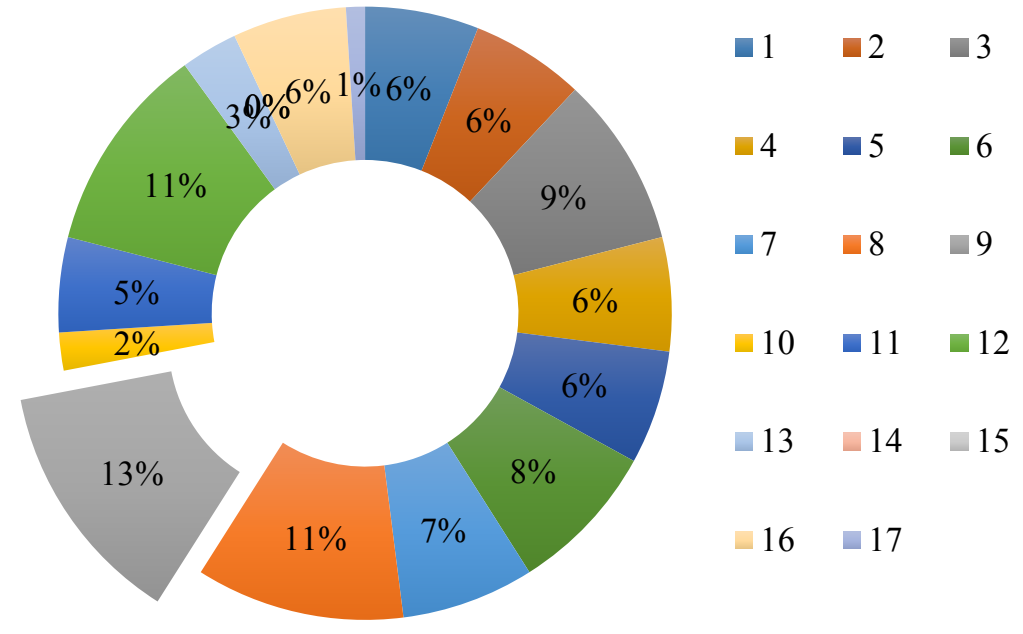

Fig. 1. The relative importance of SDGs to explain differences in the welfare of countries Source: World Happiness Report 2020 [2]

SDGs depend on the development and dissemination of innovative technologies. From this point of view, innovation and creativity are not in themselves goals, but means and tools for creating solutions to development problems and, being at the centre of the system, affect many SDGs.

Based on the above, for the development of the national system, «sustainable development - security» should be considered innovation policy as a set of management tools for targeted implementation of innovations that will promote sustainable development. The need to analyze the innovative dimension of the national system "sustainable development - security» is because the narrowing of national security to the militarypolitical aspect concerning national interests in security and defence is a wrong approach in current conditions. In this context, innovation security can be a component that connects research in the interests of both national security and its high-quality socio-economic development.

In the context of achieving the SDGs should also take into account the results of the analysis of innovation policy, considered in the study [3]:

1) the policy of innovation development should be based on a broader definition of innovation, recognizing the importance of organizational and social innovations and innovations in public administration, but at present, it remains focused mainly on technology; the same applies to the existing innovation model, which mainly reflects the 
linear way of innovation, exaggerating the importance of research compared to the daily practice of firms;

2) policy should recognize the importance of involving stakeholders in the innovation process and seek to identify a wide range of actors and build effective partnerships around essential topics;

3) internal organizational dynamics are poorly considered in innovation policy, partly due to its technological orientation and linear model of innovation;

4) politics is often a top-down approach, and the interconnected nature of players and processes at the micro, meso and macro levels is poorly defined.

As a result of the integrated nature of SDGs, new innovative approaches are discussed in a study [4] based on the following broad strategies:

- mission-oriented innovations include the implementation of network research programs at the national and international levels, as well as the creation of unique organizational structures that can guide innovation to achieve specific SDGs;

- pro-poor and inclusive innovations: expanding the benefits of innovation and building on the ideas of innovation for the bottom of the pyramid of needs through new concepts, inexpensive labour and large-scale production;

- grass-roots innovation: expanding the range of subjects of the innovation process to attract grass-roots innovation movements; this approach focuses on the practice of innovation in both technology and service delivery;

- social innovation: the transition from technological to social innovation, focusing on organizational innovation and new social practices aimed at improving welfare (for example, in business models, industrial practices and finance and the provision of public services);

- open and joint innovations with digital support: promotion of open digital cooperation; such innovative approaches absorb and recombine many sources and forms of knowledge, primarily through the digital support of open collaboration.

As a result of understanding the importance of SDGs, a scientific and practical approach to policy coherence for sustainable development (PCSD) can be considered. OECD experts define PCSD as «an approach and tool for the systematic integration of economic, social and environmental aspects of sustainable development at all stages of domestic and international policy-making» [5]. The main goals of PCSD are as follows:

- promoting synergies in all areas of economic, social and environmental policy;

- identification of compromises and harmonization of domestic policy goals with international goals;

- elimination of the negative consequences of domestic policy for the SDGs.

Given the importance of innovation development, as well as the national characteristics of the relationship between it and the SDGs, it is advisable to consider the methodology of coherence of innovation policy for sustainable development (innovation policy coherence for sustainable development, IPCSD).

Accordingly, the security of the innovative component of sustainable development can be defined as the level and dynamics of innovative development that protect national interests from threats arising from domestic and global trends of socio-economic processes and targeted actions of foreign agents, based on competitive results of scientific, technical and innovative activities embodied in products (services).

\section{Innovation policy coherence for sustainable development context}

We propose to consider the context of innovation policy coherence for sustainable development (IPCSD) on the basis of such ideas of theorists of economic science, 
innovation and strategic management.

1. Schumpeter's ideas about competition based on innovation and their analysis as a major factor in economic development. Within this approach, innovations are the basis of competition and a factor in shaping the structure of industry markets. Accordingly, we can consider innovation as a factor in the dynamics of markets of the national economy, which, depending on the effectiveness of coordination management, creates opportunities or threats.

2. Hayek's concept, within which the competitive market is interpreted as a special information environment that identifies, uses and coordinates the use of knowledge of many independent participants.

3. The concept of Freeman's national innovation system. According to this concept, the national innovation system is a set of institutions that individually and comprehensively implement the functions of creating and disseminating new technologies, forming the basis for the formation and implementation by the government of policies that affect the innovation process. In developed countries, effective mechanisms ensure high market efficiency and low transaction costs. Due to such mechanisms, competition in these countries is based on new knowledge and technologies (search for knowledge according to the concept of Hayek), which changes the logic of processes in the economy and innovation system.

4. Understanding of innovation policy within a number of schools of strategic planning, linking the following aspects: reaction to changes in the external environment (reactive process); transition to a new stable position - a configuration with a new set of strategies, structures and principles (proactive process).

5. Kramer's O-ring theory. In the original, the O-ring is a standard part for sealing valves and other moving mechanisms. In 1986, during the launch of the shuttle «Challenger», damage to one of these rings led to the explosion and death of seven astronauts.

Kramer argues that the production of goods is like launching a space shuttle: even creating a simple product in the economy requires the coordinated work of manufacturers, accountants and marketers, etc., and failure at least one stage means that the product will not be successful.

From these positions, the O-ring theory, in particular, explains the differences in GDP per capita between countries, which cannot be explained by differences in the stock of physical or human capital. Due to the fact that in developed countries, it is more profitable to use technologically more complex processes, small differences in the skills of workers through the O-ring mechanism turn into greater differences in productivity between countries. Derived from the theory of the O-ring is the theory of disorganization, developed by Kramer in collaboration with prof. Blanchard. In the production chains of a planned economy, the relationship between firms was often specific: many firms had only one supplier and one buyer.

6. The strategy of the «blue ocean» of K. Chan and R. Moborn, which can be adapted to the needs of the system «sustainable development - security». According to the strategy's authors, the «blue ocean» is a new non-competitive market based on new value. We propose to use the «blue ocean» strategy to build a national system of «sustainable development - security».

\section{Principles of innovation policy coherence for sustainable development}

It is proposed to implement the conceptual provisions of innovation policy coherence for sustainable development (IPCSD) based on: 
- adapted principles of sustainable development;

- principles of the relationship «sustainable development - security».

These principles include the following.

1. The principle of consistency of development strategy with all available strategies (sectoral, territorial, resource). This principle determines the degree of consistency of the step-by-step implementation of the overall innovation strategy with the strategy of safe development.

2. The principle of interaction of the strategy of safe development with the forecasted changes of the external environment (technological dynamics). It should be based on the compliance of the subsystem development strategy with the projected changes in indicators (national and international dimensions) to minimize threats and realize the potential of the external environment.

3. The principle of interaction of the strategy of sustainable, safe development of the state with its innovative capabilities. This principle determines the potential for the formation of resources for innovative development and the compliance of development strategies with resources.

4. The principle of the reality of the development strategy determines the strategic opportunities in the implementation of complex innovation and investment projects in a certain perspective, in the formation of the required amount of resources.

5. The principle of determining the acceptable level of risk (strategic risk corridor of development) associated with the implementation of selected development strategies (set of strategies). Based on this principle, the acceptability of the level of risks for the activity is determined in terms of the possible size of losses and the generation of threats to strategic security.

6. The principle of economic and social efficiency of the development strategy. It shows compliance with the strategic target settings, image, level of control over the activities of functional institutions.

7. The principle of system solutions. SSM in the field of innovation covers activities that combine the interconnected provision of political, economic and military leadership, as well as diplomacy and other political and legal aspects.

8. The principle of technological relationships. Breakthrough innovations can not only significantly change the technical and technological foundations of the industry but also markets, the composition and roles of actors, as well as the foundations of the economy.

9. The principle of the national (local) orientation of innovation development. For development, it is necessary to choose such technological industries that will be related to the existing potential, welfare issues and build a solid foundation for new technologies and areas of development relevant to a particular country (region).

10. The principle of strategic orientation, which provides for the inclusion of the innovation component in programs and development strategies. Strategic priorities set longterm guidelines for the development of innovation entities, as well as guidelines for financing the sector of basic and applied science and support for innovative communications. Strategic management culture is important within this principle.

\section{Conclusion}

The role of innovation policy in strengthening national security in the context of achieving the SDGs of the national economy is often ignored. Therefore, there is a need to analyze the essence of the innovative component of the relationship between sustainable development and national security. In this context, innovation policy is the component that directs innovation activity to meet the interests of both national security and socio-economic development of the country. Given the current importance of innovation for sustainable 
development, relevant national characteristics, as well as from an applied point of view, it is important to harmonize innovation policy with the SDGs, which provides support for science and innovation priorities and measurements of sustainable development.

\section{References}

1. D. Zelinka, B. Amadei, International Journal of System Dynamics Applications, 8, 1 (2019)

2. J. F. Helliwell, R. Layard, J. Sachs, Jan-Emmanuel De Neve eds. World Happiness Report 2020 (New York, Sustainable Development Solutions Network, 2020) URL: https://worldhappiness.report/ed/2020/sustainable-development-and-human-wellbeing/\#fnref21 (2020)

3. C. Makó, M. Illéssy, QuInnE Working Paper, 1 (2015)

4. New innovation approaches to support the implementation of the sustainable development goals. United Nations. https://unctad.org/en/PublicationsLibrary/dtlstict2017d4_en.pdf (2017)

5. Policy Coherence for Sustainable Development 2019. Empowering People and Ensuring Inclusiveness and Equality Highlights. OECD. URL: https://www.oecd.org/gov/pcsd/policy-coherence-for-sustainable-developmenthighlights-2019.pdf (2019)

6. V. Omelyanenko, O. Braslavska, N. Biloshkurska, M. Biloshkurskyi, N. Kliasen, O. Omelyanenko, International Journal of Computer Science and Network Security, 21, 9 (2021)

7. V. Omelyanenko, National strategic innovation security policy making (theoretical review) (Tallinn, Teadmus, 2020)

8. V. Omelyanenko, Technology audit and production reserves, $\mathbf{3 / 5}$ (41) (2018) 